\title{
Primary Adenocarcinoma of the Colon with Metastases to the Mandible and Liver: A Case Report
}

\author{
Adenocarcinoma Primario de Colon con Metástasis en \\ Mandíbula e Hígado: Reporte de un Caso
}

\begin{abstract}
Ana Luiza Dias Leite de Andrade*; Manuel Antonio Gordón-Núñez ${ }^{* *}$ Rodrigo Cavalcanti Duarte Galvão**; Gustavo Alberto Freire Fernades ${ }^{* * * *}$; Edilmar de Moura Santos ${ }^{* * * *}$ \& Hébel Cavalcanti Galvão*
\end{abstract}

ANDRADE, A. L. D. L.; GORDÓN-NÚÑEZ; M. A.; GALVÃO, R. C. D.; FERNANDES, G. A. F.; SANTOS, E. M. \& GALVÃO, H. C. Primary adenocarcinoma of the colon with metastases to the mandible and liver: A case report. Int. J. Odontostomat., 9(2):307-312, 2015.

ABSTRACT: Metastatic lesions to the mandible may be originated from primary tumors elsewhere in the body. However, metastatic colonic carcinomas to this bone have been described infrequently. We report the case of a 71-year-old man with an adenocarcinoma in the sigmoid colon with liver metastasis. The patient underwent chemotherapy with indication of sigmoidectomy and retroperitoneal lymphadenectomy. One year and four months after the first metastatic diagnosis, the patient presented a tumor mass in the body and branch of the right mandible. Histopathological and immunohistochemical analysis with monoclonal antibodies specific for CEA, CK20, CDX-2, and vilin were compatible with the diagnosis of moderately differentiated metastatic adenocarcinoma with colonic origin. However, due to the wide spread of the disease, the patient died four months later. Tumor markers have been applied in clinical practice to assist in the diagnosis and to help guide prognosis, staging and treatment of cancer. The management of metastatic lesions remains a controversial issue and the development of new and more specific markers of gastrointestinal differentiation that may promote early diagnosis, are of continuous interest.

KEY WORDS: adenocarcinoma; colonic neoplasms; mandible; neoplasm metastasis.

\section{INTRODUCTION}

Although any site can be affected by metastasis from primary tumors elsewhere in the body, the oral cavity and oropharynx are very uncommon sites of metastatic lesions, accounting for only $1-2 \%$ of oral malignancies (Meyer \& Shklar, 1965; van der Waal et al, 2003). Among other regions of oral cavity, the mandible is an uncommon site for metastatic lesions and in about $70 \%$ of patients, the lesion is histologically an adenocarcinoma (Meyer \& Shklar; Kuttan et al., 2006).

Almost all types of malignancy may metastasize to the oral region. However, the most common primary sites are the lung, kidney, and prostate for men, and the breast, female genital organs, and kidney for women (Hirshberg et al., 2008). Colon carcinoma is the most frequent malignant gastrointestinal neoplasm, and one of the commonest tumors in the general population (Alvarez-Alvarez et al., 2006). This disease results from the accumulation of genetic mutations that promote the transformation of the normal colonic epithelium in carcinogen. The first step is the development of adenomatous polyps with subsequent progression to malignancy, invasion and metastasis (Hamilton \& Aaltonen, 2000).

In this article, we report a case of patient with an advanced colon adenocarcinoma who developed metastasis to the liver and mandibular bone. Furthermore, we discuss the main aspects related to

* Department of Dentistry, Federal University of Rio Grande do Norte, Natal, Brazil.

** Department of Dentistry, State University of Paraíba, Araruna, Brazil.

*** School of Medicine, Potiguar University, Natal, Brazil.

${ }_{* * * *}$ Oncological surgeon, Heart Hospital of Natal, Natal, Brazil.

${ }^{*}$ Radiation Oncologist of Riograndense Northern League Against Cancer, Professor, Potiguar University, Natal, Brazil. 
the pathogenesis, clinical findings, immunohistochemical markers and therapy modalities used in disease treatment.

\section{CASE REPORT}

A 71-year-old white man was diagnosed with an advanced adenocarcinoma of the sigmoid colon with indication of sigmoidectomy and retroperitoneal lymphadenectomy. The chemiluminescence test for serum carcinoembryonic antigen (CEA) level showed value of $99.2 \mathrm{mg} / \mathrm{mL}$ (normal reference range $=6.2$ $\mathrm{mg} / \mathrm{mL}$ ).

In order to assess the presence of tumor distant metastases, the patient underwent abdominal/pelvis computed tomography (CT). Radiological examination revealed the presence of multiple hypodense nodular formations in the liver parenchyma with increased organ size (Fig. 1). Faced with such evidence, incisional biopsy of liver tissue was performed, and the specimen submitted for histopathological and immunohistochemical analysis. For this study, a panel of antibodies was used and revealed positivity profile for CK20, CDX-2, CEA and villin, which was compatible with the diagnosis of moderately differentiated metastatic adenocarcinoma. The patient received 7 cycles of 5-fluorouracil, leucovorin, and oxaliplatin (FOLFOX) chemotherapy. However, as he developed residual neuropathy, oxaliplatin was suspended and 3 cycles of 5-fluorouracil and leucovorin chemotherapy was started. Then, the patient was managed with 5fluorouracil, leucovorin, and irinotecan (FOLFIRI) chemotherapy as second line treatment, in order to assess his response with this treatment.

One year and four months after the first metastatic diagnosis, the patient presented a tumor mass in the body and branch of the right mandible. Helical CT with contrast was performed in the axial plane with $3 \mathrm{~mm}$ thick cuts in portions supra and infrahyoid. An osteolytic lesion was observed with cortical disruption and extension into adjacent soft tissue, measuring about $4.8 \times 4.3 \mathrm{~cm}$ in the body of the right mandible. During the surgical biopsy, because of the large size of the lesion and the occurrence of uncontrolled bleeding, a hemimandibulectomy was performed (Fig. 2).

Histopathological examination of the specimen revealed the presence of numerous strands forming glan-

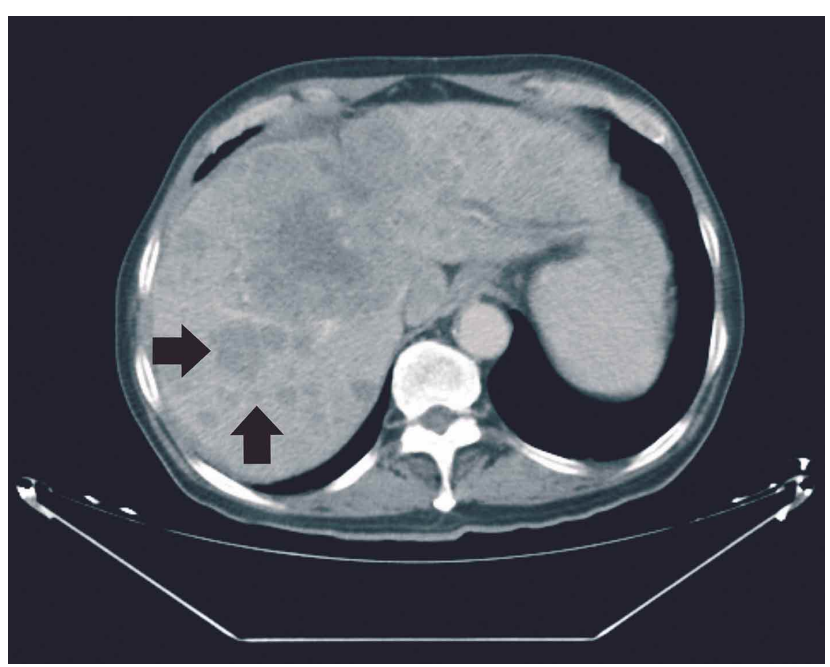

Fig. 1. CT scan demonstrates the presence of hypodense nodular formations in the liver parenchyma (arrows).

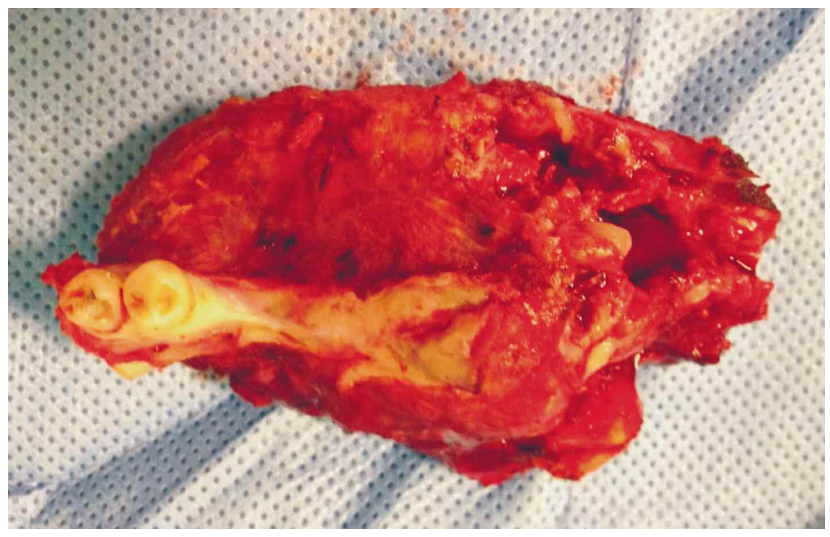

Fig. 2. Macroscopic aspect of the hemimandible removed.

dular epithelial structures arranged in a papillary or cribriform architectural growth patterns. Individually, the neoplastic cells showed large nucleoli, increased nuclear/ cytoplasmic ratio, enlarged, pleomorphic and hyperchromatic nuclei, as well as many typical and atypical mitotic figures. The supporting stroma was dense fibrous and permeated by areas of moderate chronic lymphocytic inflammatory infiltrate in addition to multinucleated giant cells. Comedonecrosis and dystrophic calcification were also observed (Fig. 3A-B).

Additional immunohistochemistry performed on the specimen demonstrated that the lesion expressed CK20, CDX-2, CEA and villin. On the other hand, the specimen showed negative reaction for CK7, TTF-1 and GCDFP-15 (Fig. 3C-F). Based on histopathologic and immunohistochemical findings, the diagnosis of moderately differentiated metastatic adenocarcinoma was set. As the patient had clinical progression, it was 


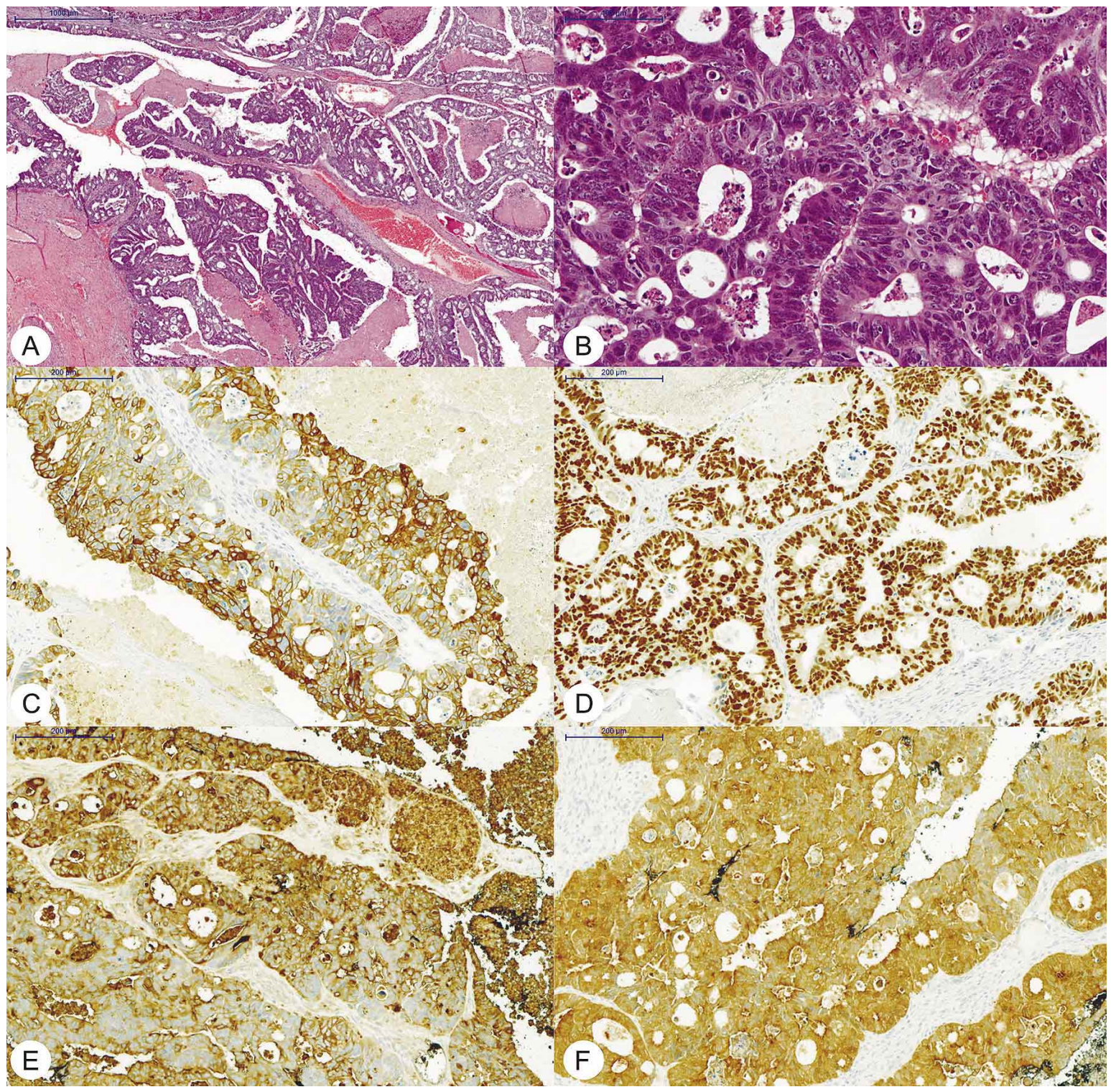

Fig. 3. A) Histopathological analysis revealed the presence of numerous strands forming glandular epithelial structures. B) Individually, the neoplastic cells showed moderate cytologic atypia (HE). C-F) Representative photomicrographs of immunohistochemical staining of CK20 (C), CDX-2 (D), CEA (E) and villin (F).

decided to return to treatment with the use of FOLFOX chemotherapy with adjuvant radiotherapy. Unfortunately, due to the wide spread of the disease, the patient died four months later.

\section{DISCUSSION}

One important aspect of the biology of cancer is the development of metastases and their diagnosis is always challenging for both clinician and the pathologist, due to its rarity and complexity (Servato et al., 2013; Soares et al., 2011). Kwon et al. (2006), proposed some criteria for metastatic tumor diagnosis. Firstly, the primary tumor must be known and histologically verified. Then, the metastatic neoplasm must be of the same histological subtype as the primary tumor. Finally, the possibility of direct local spread from the primary tumor must be excluded.

Metastatic disease is usually found between the fifth and seventh decade of life and there are no significant differences regarding sex in the re-ported 
ANDRADE, A. L. D. L.; GORDóN-NÚÑEZ; M. A.; GALVÃO, R. C. D.; FERNANDES, G. A. F.; SANTOS, E. M. \& GALVÃO, H. C. Primary adenocarcinoma of the colon with metastases to the mandible and liver: A case report. Int. J. Odontostomat., 9(2):307-312, 2015.

cases located in oral region (Valdivieso et al., 1999; van der Waal et al.; Kuttan et al.). Individuals with mandibular metastases may be asymptomatic, or may present signs and symptoms, including complain of jaw or tooth pain, paresthesia (unilateral or bilateral numbness of the chin) or loosening of teeth (Daley \& Armstrong, 2007). The patient of this case had 71-yearold which is in concordance with the age range previously described in the literature, and he did not present any complaint of the lesion in the mandible, but we believe it is also due to its severe systemic condition.

The pathogenesis of metastasis remains unclear, but according to Gubitosi et al. (2009), metastatic spread from colonic carcinoma is quite predictable, initially through lymphatic vessels, followed by the hematogenous route. One potential route whereby the tumor cells spread from the abdominal primary site to the oral tissues and bypass the right heart-lung capillary bed is via vertebral plexus of veins (Daley \& Armstrong). In addition, metastases seem to prefer the hematopoietically active marrow of skeletal bone, because it is rich with sinusoidal vascular spaces that permit tumor cell penetration. Although the mandible is not a site of active marrow in humans, particularly in older individuals, because of the greater likelihood of a marrow reserve in its posterior domain, the condyle, angle, and ramus of this bone are affected in $32.5 \%$ of cases (Hirshberg et al., 1994; Mason et al., 2005).

Clinically, gastrointestinal metastatic cancers to the oral region have been associated with a poor prognostic sign, usually indicating widespread metastases (van der Waal et al.; Daley \& Armstrong). Once distant metastases are diagnosed, few patients survive five years and most of them die within one year (Daley \& Armstrong). Colorectal carcinoma has a recognized metastatic pattern to metastasize the liver or lungs (Ghetie et al., 2008), and it is not uncommon that multiple sites are involved before the oral presentation (Bhaskaran et al., 2011), as it was observed in the present case. In a previous study, among 29 cases of oral/oropharyngeal metastases that were retrieved, all patients with stomach and colon cancers had he-patic metastasis before or simultaneously with oral metastases. Along with the lungs, the liver is one of the most frequently involved organs in hematogenous dissemination (Shin et al., 2012).

It is established in the literature that in the setting of metastatic carcinoma presenting within the oral cavity, the management begins with a tissue diagnosis (Mason et al.). In this perspective, appropriate diagnostic methods should be realized and po-tentially unnecessary medical procedures should be prevented (Shin et al.). In cases of carcinomas of unknown primary, clinicopathologic correlation and a panel of standard immunostains help define the primary site, and direct appropriate treatment (Li \& Folpe, 2004). Immunohistochemically, the present case was negative for CK7 and positive for CK20, CDX-2, CEA and villin.

It is well documented that the evaluation of the coordinate expression of CK7 and CK20 can be helpful in determining and distinguishing the primary sites of origin of metastatic carcinomas (Meer \& Altini, 2007), including breast, ovarian, and lung primaries (usually CK7+/CK20-), as well as colorectal primaries (usually CK7-/CK20+). However, occasionally colorectal carcinomas may show significant CK7 expression and expression of CK20 may be seen in a variety of noncolorectal adenocarcinomas (Li \& Folpe).

According to Werling et al. (2003) the coordinate expression of the intestinal cytoskeletal protein villin and the transcription factor product of the CDX-2 homeobox gene in different neoplasms can be exploited to characterize metastatic carcinomas. Compared with villin, CDX-2 demonstrated superior sensitivity and comparable specificity to be used as a marker of gastrointestinal adenocarcinomas. Tumors expressing both CDX-2 and villin in a variable pattern of intensity may have origin anywhere in the gastrointestinal tract, whereas uniform intense expression of CDX-2 with or without villin favors colorectal origin.

Serum CEA levels are a clinical prognostic factor that can be applied in the follow-up evaluation of patients with colon cancer (Jung et al., 2013). Although many tumors may secrete CEA, monoclonal antibodies generated against colon carcinoma-specific CEA are available to recognize an epitope present only on CEA of colorectal adenocarcinoma origin, enabling specific targeting and identification of the tissue of origin (Nitzan et al., 1990). Previously studies in patients with colorectal carcinoma have demonstrated the prognostic effect of preoperative CEA levels and the usefulness of postoperative CEA monitoring for early detection of recurrence after curative surgery and for assessment of the response to chemotherapy in metastatic colorectal cancer (Quentmeier et al., 1989; Bruinvels et al., 1994). Commonly, there is observed an increase 
ANDRADE, A. L. D. L.; GORDóN-NÚÑEZ; M. A.; GALVÃO, R. C. D.; FERNANDES, G. A. F.; SANTOS, E. M. \& GALVÃO, H. C. Primary adenocarcinoma of the colon with metastases to the mandible and liver: A case report. Int. J. Odontostomat., 9(2):307-312, 2015.

in the preoperative CEA level, as compared with the early postoperative decrease in the level of this marker (Jung etal.). However, Hsu (2006) reported a case of a patient in whom extremely unusual elevation of CEA and suggested that: elevation of CEA is not necessarily well correlated with presence of metastatic colon cancer; some patients may live with elevated CEA for years without evidence of recurrence or metastasis; and aggressive chemotherapy may not be necessary in patients with only elevated CEA.

Treatment and prognosis of metastatic tumors varies and depends on the level of dissemination of the neoplastic cells and their location (Kuttan et al.; Soares et al.). The advent of novel chemotherapeutic agents (particularly, the FOLFOX and FOLFIRI regimens) has been useful as a palliative benefit and has improved survival in patients with advanced colorectal cancer (Mason et al.). Surgical resection is usually an option for patients with only oral metastasis, but in cases of tumors widely disseminated, palliative radiotherapy is recommended (van der Waal et al.). Moreover, in patients with terminal disease and when they have late diagnosis of widespread disease, the treatment should primarily be focused at relief from chronic pain (Kuttan et al.).

In conclusion, this case describes the clinical course of a patient with metastatic adenocarcinoma of the colon to the liver and mandible, emphasizing the value of immunohistochemical techniques in the diagnosis. Tumor markers have been applied in clinical practice to assist in the diagnosis and to help guide prognosis, staging and treatment. The management of metastatic lesions remains a controversial issue and the development of new and more specific markers of gastrointestinal differentiation that may promote early diagnosis, are of continuous interest.

ANDRADE, A. L. D. L.; GORDÓN-NÚÑEZ; M. A.; GALVÃO, R. C. D.; FERNANDES, G. A. F.; SANTOS, E. M. \& GALVÃO, H. C. Adenocarcinoma primario de colon con metástasis en mandíbula e hígado: Reporte un de caso. Int. J. Odontostomat., 9(2):307-312, 2015.

RESUMEN: Las lesiones metastásicas de la mandíbula pueden surgir de los tumores primarios en cualquier partes del cuerpo. Sin embargo, el carcinoma metastásico de colon de este hueso se han reportado con poca frecuencia. Presentamos el caso de un hombre de 71 años de edad, con un adenocarcinoma de colon sigmoide con metástasis en el hígado. El paciente fue sometido a quimioterapia con indicación de sigmoidectomía y linfadenectomía retroperitoneal. Un año y cuatro meses después de la emisión del primer diagnóstico de la metástasis, el paciente presentaba una masa tumoral en el cuerpo y rama de la mandíbula derecha. El análisis histopatológico e inmunohistoquímico con anticuerpos monoclonales específicos para CEA, CK20, CDX-2, y vilin fueron compatibles con el diagnóstico de adenocarcinoma moderadamente diferenciado metastásico originario en el colon. Sin embargo, debido a la amplia propagación de la enfermedad, el paciente murió cuatro meses más tarde. Los marcadores tumorales se han aplicado en la práctica clínica para ayudar en el diagnóstico y ayudar a orientar el pronóstico, la estadificación y tratamiento del cáncer. Gestión de las lesiones metastásicas sigue siendo un tema controvertido, y el desarrollo de marcadores nuevos y específicos que promueven la diferenciación del diagnóstico precoz gastrointestinal, son de interés continuo.

PALABRAS CLAVE: adenocarcinoma, neoplasias del colon, mandíbula, metástasis neoplásica.

\section{REFERENCES}

Alvarez-Alvarez, C.; Iglesias-Rodríguez, B.; Pazo-Irazu, S. \& Delgado-Sánchez-Gracián, C. Colonic adenocarcinoma with metastasis to the gingiva. Med. Oral Patol. Oral Cir. Bucal, 11(1):E85-7, 2006.

Bhaskaran, A.; Harding, S. \& Courtney, D. An unusual presentation of metastatic colon adenocarcinoma in the oral cavity. Case Rep. Dent., 2011:357518, 2011.

Bruinvels, D. J.; Stiggelbout, A. M.; Kievit, J.; van Houwelingen, H. C.; Habbema, J. D. \& van de Velde, C. J. Follow-up of patients with colorectal cancer. A metaanalysis. Ann. Surg., 219(2):174-82, 1994.
Daley, T. D. \& Armstrong, J. E. Oral manifestations of gastrointestinal diseases. Can. J. Gastroenterol., 21(4):241-4, 2007.

Ghetie, C.; Davies, M.; Cornfeld, D.; Suh, N. \& Saif, M. W. Expectoration of a lung metastasis in a patient with colorectal carcinoma. Clin. Colorectal Cancer, 7(4):283-6, 2008.

Gubitosi, A.; Moccia, G.; Malinconico, F. A.; Gilio, F.; Iside, G.; Califano, U. G.; Foroni, F.; Ruggiero, R.; Docimo, G.; Parmeggiani, D. \& Agresti, M. Unusual metastasis of left colon cancer: considerations on two cases. Acta Biomed., 80(1):80-2, 2009. 
ANDRADE, A. L. D. L.; GORDÓN-NÚÑEZ; M. A.; GALVÃO, R. C. D.; FERNANDES, G. A. F.; SANTOS, E. M. \& GALVÃO, H. C. Primary adenocarcinoma of the colon with metastases to the mandible and liver: A case report. Int. J. Odontostomat., 9(2):307-312, 2015.

Hamilton, S. R. \& Aaltonen, L. A. World Health Organization classification of tumours. Pathology and genetics of tumours of the digestive system. Lyon, IARC Press, 2000.

Hirshberg, A.; Leibovich, P. \& Buchner, A. Metastatic tumors to the jawbones: analysis of 390 cases. J. Oral Pathol. Med., 23(8):337-41, 1994.

Hirshberg, A.; Shnaiderman-Shapiro, A.; Kaplan, I. \& Berger, R. Metastatic tumours to the oral cavity - pathogenesis and analysis of 673 cases. Oral Oncol., 44(8):743-52, 2008.

Hsu, T. C. Unusual elevation of CEA in a patient with history of colon cancer. Jpn. J. Clin. Oncol., 36(12):811-3, 2006.

Jung, T. D.; Yoo, J. H.; Lee, M. J.; Park, H. K.; Shin, J. H.; An, M. S.; Ha, T. K.; Kim, K. H.; Bae, K. B.; Kim, T. H.; Choi, C. S.; Oh, M. K. \& Hong, K. H. Prognostic significance of the decreased rate of perioperative serum carcinoembryonic antigen level in the patients with coIon cancer after a curative resection. Ann. Coloproctol., 29(3):115-22, 2013.

Kuttan, N. A.; Flemming, D. K.; Dane, J. N. \& Ang, D. B. Metastatic lesion of the anterior mandible with an occult primary: a case report. Spec. Care Dentist., 26(2):7680, 2006.

Kwon, M. S.; Ko, S. O.; Cho, N. P.; Kim, O. H.; Shin, H. K.; Baek, J. A. \& Leem, D. H. Gastric signet-ring cell adenocarcinoma metastatic to the gingiva: a case report. Oral Surg. Oral Med. Oral Pathol. Oral Radiol. Endod., 102(1):62-6, 2006.

Li, M. K. \& Folpe, A. L. CDX-2, a new marker for adenocarcinoma of gastrointestinal origin. Adv. Anat. Pathol., 11(2):101-5, 2004.

Mason, A. C.; Azari, K. K.; Farkas, L. M.; Duvvuri, U. \& Myers, E. N. Metastatic adenocarcinoma of the colon presenting as a mass in the mandible. Head Neck, 27(8):729-32, 2005.

Meer, S. \& Altini, M. CK7+/CK20- immunoexpression profile is typical of salivary gland neoplasia. Histopathology, 51(1):26-32, 2007.

Meyer, I. \& Shklar, G. Malignant tumors metastatic to mouth and jaws. Oral Surg. Oral Med. Oral Pathol., 20:350-64, 1965.

Nitzan, D. W.; Livni, N.; Marmary, Y.; Ben-Baruch, N.; Sela, J. \& Catane, R. The use of monoclonal anti-CEA antibody immunohistochemistry in detecting the origin of oral cavity metastasis. Int. J. Oral Maxillofac. Surg., 19(3):162-4, 1990.
Quentmeier, A.; Schlag, P.; Hohenberger, P.; Schwarz, V. \& Abel, U. Assessment of serial carcinoembryonic antigen: determinations to monitor the therapeutic progress and prognosis of metastatic liver disease treated by regional chemotherapy. J. Surg. Oncol., 40(2):112-8, 1989.

Servato, J. P.; de Paulo, L. F.; de Faria, P. R.; Cardoso, S. V. \& Loyola, A. M. Metastatic tumours to the head and neck: retrospective analysis from a Brazilian tertiary referral centre. Int. J. Oral Maxillofac. Surg., 42(11):1391-6, 2013.

Shin, S. J.; Roh, J. L.; Choi, S. H.; Nam, S. Y.; Kim, S. Y.; Kim, S. B.; Lee, S. W. \& Cho, K. J. Metastatic carcinomas to the oral cavity and oropharynx. Korean J. Pathol., 46(3):266-71, 2012.

Soares, A. B.; Thomaz, L. A.; Duarte, M. T.; de Camargo de Moraes, P. \& de Araújo, V. C. Metastatic adenocarcinoma of the colon: early manifestation in gingival tissue. Head Neck Pathol., 5(2):140-3, 2011.

Valdivieso, M.; Ostria, J. \& Lobos, N. Oral and maxillofacial metastases of neoplams from other sites of the body. Med. Oral, 4(5):583-7, 1999.

van der Waal, R. I.; Buter, J. \& van der Waal, I. Oral metastases: report of 24 cases. Br. J. Oral Maxillofac. Surg., 41(1):3-6, 2003.

Werling, R. W.; Yaziji, H.; Bacchi, C. E. \& Gown, A. M. CDX2, a highly sensitive and specific marker of adenocarcinomas of intestinal origin: an immunohistochemical survey of 476 primary and metastatic carcinomas. Am. J. Surg. Pathol., 27(3):30310, 2003.

Correspondence to:

Ana Luiza Dias Leite de Andrade

Universidade Federal do Rio Grande do Norte

Departamento de Odontologia

Av. Senador Salgado Filho, 1787

Lagoa Nova - Natal - RN

CEP 59056-000

BRAZIL

Email: ana_luiza_dla@hotmail.com

Received: 03-09-2014

Accepted: 28-05-2015 